Research Article

\title{
Thermomechanical Optimization and Comparison of a Low Thermal Inertia Mold with Rectangular Heating Channels and a Conventional Mold
}

\author{
Jean Collomb ${ }^{1 D},{ }^{1,2}$ Pascale Balland, ${ }^{1}$ Pascal Francescato, ${ }^{1}$ Yves Gardet, ${ }^{2}$ David Leh, ${ }^{2}$ \\ and Philippe Saffré ${ }^{1}$ \\ ${ }^{1}$ Univ. Savoie Mont Blanc, SYMME, 74000 Annecy, France \\ ${ }^{2}$ CT1 Company, Compose Group, 8 bis avenue de la Gare, 01100 Bellignat, France
}

Correspondence should be addressed to Jean Collomb; jean.collomb@univ-smb.fr

Received 17 December 2018; Accepted 10 April 2019; Published 2 May 2019

Academic Editor: Amelia Almeida

Copyright ( 92019 Jean Collomb et al. This is an open access article distributed under the Creative Commons Attribution License, which permits unrestricted use, distribution, and reproduction in any medium, provided the original work is properly cited.

\begin{abstract}
Molds used to manufacture high-performance composites currently do not meet the demand of manufacturers in terms of production rate due to massive mold designs, using straight-through heating channels, that are not thermally reactive. In this paper, using a thermal finite element model, the thermomechanical responses of an existing massive and conventional mold is observed; then, thermomechanical optimizations are carried out on a circular heating channel mold and on a rectangular heating channel mold. The objective of this paper is two-fold: (i) confirm the need to change design rules for molds considering technological aspects (e.g., pressure drop and fluid nature) and (ii) validate the advantages of an innovative concept of a low thermal inertia mold with rectangular heating channels. Results of this study confirm the need to reduce the mass of structures to increase heating rates and the importance of taking into account technological data (heat transfer fluid, pressure drop) to ensure the optimal convective exchange. After optimization, a decrease greater than $75 \%$ in heating time for the circular channel model and up to $88 \%$ for the rectangular channel model was observed. Moreover, the antagonistic nature between heating rate and thermal homogeneity of the molding surface and between heating rate and mechanical strength is confirmed.
\end{abstract}

\section{Introduction}

Industries producing high-performance composite structures, such as aeronautics, whose new commercial aircraft consists of more than $50 \%$ composites, have growth that requires an increase in production rates while limiting production costs and energy consumption and ensuring the structural quality of the parts. In addition, current global environmental standards impose a significant reduction in greenhouse gas emissions. In this context, and in partnership with the automotive and aerospace industries, developments are being made to make large-scale production lines of highperformance composites competitive in terms of the quality of the cost-production rate, from the preparation of raw materials (resins and preforms) to finishing and assembly, through the injection and/or consolidation of the composite part. Thus, metallic structural parts could be replaced with structural parts made of lighter composite materials, lightening the structures and reducing greenhouse gas emissions. Reference processes for the production of highperformance composite materials are the autoclave and injection/consolidation under pressure in a closed thermoregulated mold with heating and cooling rates of a few ${ }^{\circ} \mathrm{C} \cdot \mathrm{min}^{-1}$. The aeronautics sector tends to develop out of autoclave (OOA) processes to anticipate the increase of future production rates and to limit manufacturing costs (investment, energy, and labor costs). The conventional method for producing composites in closed tools is resin transfer molding (RTM) and involves injecting a viscous resin into a hot mold and then ejecting the consolidated part. To increase production rates and limit energy consumption, the process can be used in isothermal mode but results in 
defects in the molded parts: internal stresses and unsatisfactory surface appearance. To overcome these problems and allow the production of thermoplastic resins, mold structures can perform thermal cycling, but this is done to the detriment of the production rate and energy consumption. The mold is generally thermoregulated using a heat transfer fluid, which circulates in straight channels drilled in the structure [1]. Studies seeking to optimize tooling performance are generally conducted individually on massive mold and focus on two categories of parameters: (i) process parameters: temperatures and pressure [2-5]; (ii) mold parameters: constitutive materials [6-8], fluid network optimization [9, 10], heating channel position [11-13], conformal heating channels [14-17], profiled channels [18-20], and heating technology [21-23]. Now, with new additive manufacturing technology, it is possible to produce structures with low thermal inertia and rectangular conformable heating channels for better thermal performance. The value of this mold concept having been demonstrated numerically and experimentally [20], the objective of this paper is the thermomechanical optimization of the low thermal inertia mold concept with rectangular heating channels, taking into account technological data such as pressure drop, the nature of the heat transfer fluid, and the regulation of the thermoregulator power. This study is limited to a low-pressure composite injection.

In this study, the thermomechanical performance of a massive conventional mold was observed, then an optimization procedure was carried out on a model with circular heating channels, and finally an optimization procedure was carried out on a model with rectangular heating channels.

\section{Materials and Methods}

The approach implemented for this study is as follows:

(i) Observe thermomechanical responses on the massive conventional mold model presented in Figure 1

(ii) Optimize the geometry of this mold with circular heating channels

(iii) Optimize the geometry of the low thermal inertia mold concept with rectangular heating channels

This study was conducted on reference conventional RTM plate tooling in stainless steel, presented in Figure 1, with the geometrical and technological properties presented in Table 1. A $10 \mathrm{~mm}$ Monolux insulating plate was glued to the outer sides of the mold to limit heat loss, and a $5 \mathrm{~mm}$ steel sheet was used to construct an external box to facilitate handling and placing the plate in the press. A $3 \mathrm{~mm}$ thick carbon-epoxy composite with the usual thermal properties was present on the cavity mold.

During the injection and the cure of a composite material, the mold is generally placed in a press so that the mechanical forces related to the injection of the resin can be taken up and sufficient compaction can be ensured. In addition, a thermoregulator is generally associated with the system to heat the structure. The thermophysical principle consists in heating a heat transfer fluid via an electrical

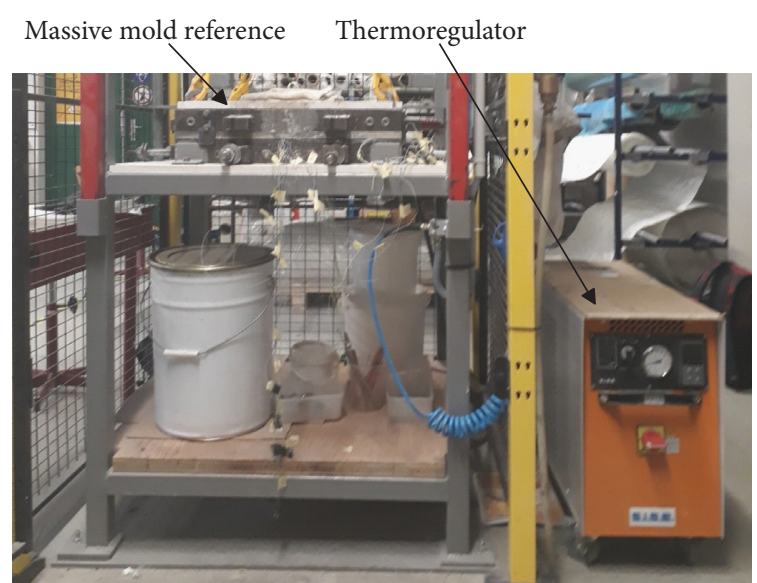

Figure 1: Massive reference mold and thermoregulator.

TABLE 1: Characteristics of reference tools and material properties.

\begin{tabular}{|c|c|c|c|}
\hline \multicolumn{3}{|l|}{ Characteristics } & Units \\
\hline \multicolumn{2}{|l|}{ Dimensions } & $570 \times 570 \times 110$ & $\mathrm{~mm}^{3}$ \\
\hline \multicolumn{2}{|l|}{ Materials } & Steel 316L & - \\
\hline \multicolumn{2}{|l|}{ Heating power } & 12 & $\mathrm{~kW}$ \\
\hline \multicolumn{2}{|l|}{ Fluid volume } & 16 & $\mathrm{~L}$ \\
\hline \multicolumn{2}{|c|}{ Composite dimensions } & $400 \times 400 \times 3$ & $\mathrm{~mm}^{3}$ \\
\hline & Steel & Insulation & Composite \\
\hline$\lambda\left(\mathrm{W} \cdot \mathrm{m}^{-1} \cdot \mathrm{K}^{-1}\right)$ & 15 & 0.18 & $\begin{array}{c}\lambda_{\mathrm{x}}=2 \\
\lambda_{\mathrm{y}}=0.2\end{array}$ \\
\hline $\mathrm{Cp}\left(\mathrm{J} \cdot \mathrm{kg}^{-1} \cdot \mathrm{K}^{-1}\right)$ & 450 & 1130 & 1000 \\
\hline$\rho\left(\mathrm{kg} \cdot \mathrm{m}^{-3}\right)$ & 7900 & 770 & 1800 \\
\hline$E(\mathrm{MPa})$ & 210000 & 3750 & - \\
\hline$v$ & 0.3 & 0.3 & - \\
\hline
\end{tabular}

power from the thermoregulatory system, and then the fluid circulates to the mold's heating channels with the pump from the thermoregulator. The fluid circulation in the mold's heating channels, coupled with a temperature gradient, induces a convective heat transfer. Figure 2 presents a representation of a mold, a press, and a thermoregulator system. The thermal and mechanical finite element models used in this study take into account these different thermophysical phenomena (fluidic, thermal, and mechanical) and technological constraints (pressure drop and operating point) to come as close as possible to the actual behaviour of the system, while avoiding an expensive fluidic model.

The study was conducted on a bidirectional representative structure (RVE: representative volume element) so that the edge effects can be ignored and to focus on the mold's heating zone, presented in Figure 3. Finite element simulations were performed using the ANSYS v.18.1 software. PLANE77 quadratic thermal elements were used for thermal simulations, a thermal mass element was used to represent the thermoregulator in terms of heating power and fluid volume, and unidirectional convective link elements joining the thermoregulator (mass element) and heating channel surface were used to represent the convective exchange. For mechanical simulations, PLANE183 quadratic elements were used. After having tested different mesh sizes, an optimal $1 \mathrm{~mm}$ mesh size was retained. 


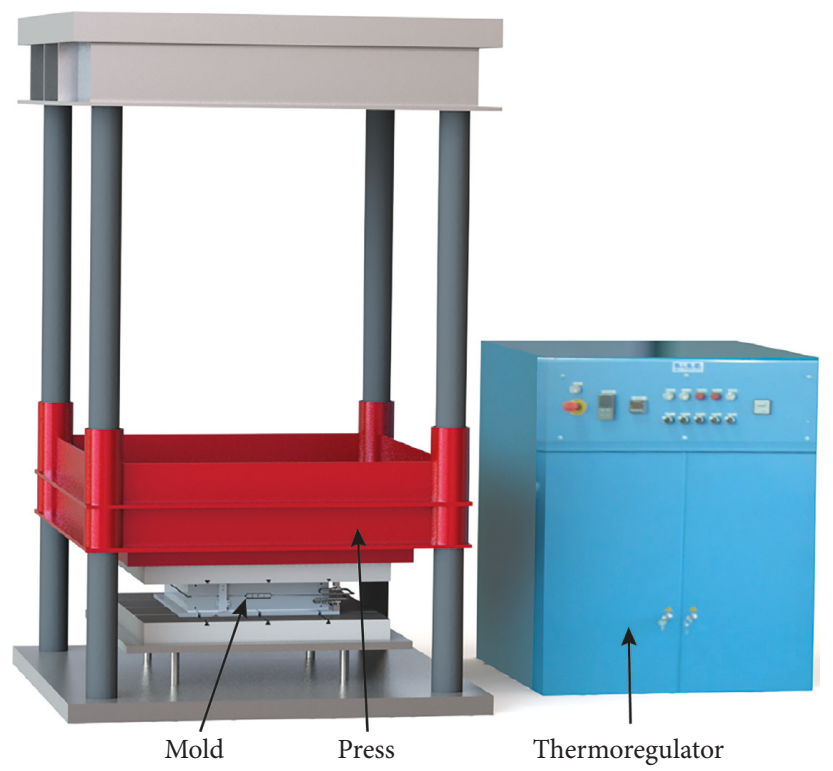

FIGURE 2: Typical system: mold, press, and thermoregulator.

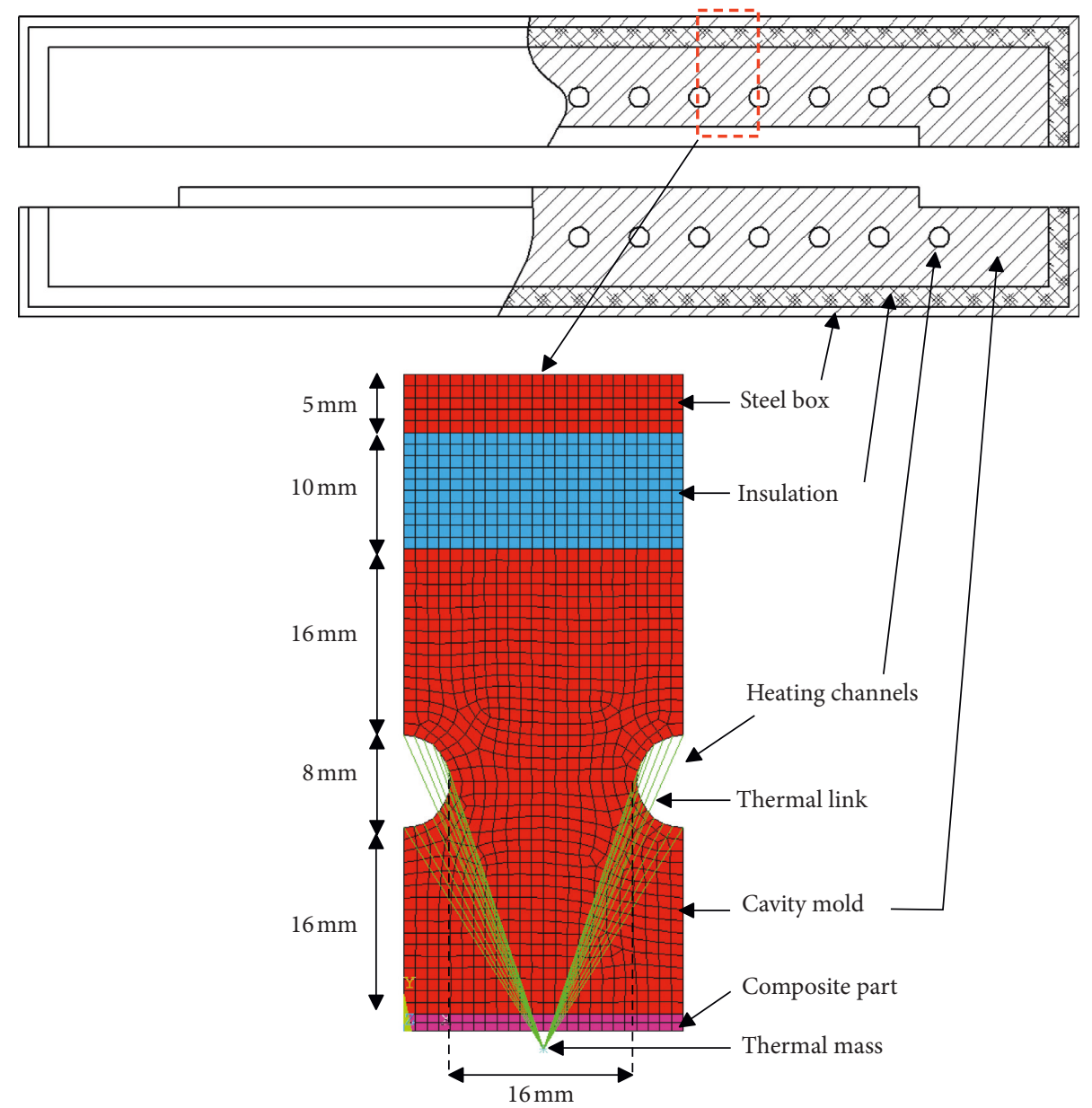

FIgURE 3: Typical injection mold and RVE modeling of conventional solid tooling.

For the thermal simulations, the initial temperature was $25^{\circ} \mathrm{C}$ and the temperature set point was $80^{\circ} \mathrm{C}$. Lateral lines and lower lines correspond to symmetry planes, and an adiabatic condition was applied: thermal flux $=0 \mathrm{~W}$. A natural convection was applied on the upper line of the outer steel sheet: temperature $=25^{\circ} \mathrm{C}$ and convection coefficient 
$h=5 \mathrm{~W} \cdot \mathrm{m}^{-2} \cdot \mathrm{K}^{-1}$. A forced convection was applied inside the heating channels via convective link elements. The convective coefficient was determined by the method presented in the Collomb et al. study [20] taking into account the characteristics of the thermoregulator pump, the nature of the fluid, and the changes in temperature. To study the influence of the heat transfer fluid, the fluid used for thermoregulation was first water and then Therminol D12 oil. The system was heated by applying a thermal power of $12 \mathrm{~kW}$ regulated by PID on the thermal element mass and corresponding to the power of the thermoregulator. The phenomena related to the crosslinking of the resin (including exothermic behaviour) were not taken into account.

For mechanical simulations, symmetry planes are preserved. The structure is considered to be in a press: the vertical displacement of the upper line of the outer sheet is blocked. A pressure of 15 bar corresponding to the injection of the resin was applied to the molding surface; 3.5 bar of pressure was applied to the heating channels, corresponding to the pressure due to the fluid circulation.

Thermomechanical responses observed for each of the models are as follows:

(i) $t$ : heating time of the cold point on the molding surface to reach $90 \%$ of the set point temperature

(ii) $\Delta T$ : maximum temperature difference on the molding surface during the heating phase

(iii) $u$ : maximum vertical displacement of the molding surface

For the massive conventional reference model, the heating time, the temperature difference, and the maximum displacement of the molding surface for water heating and oil heating are presented in Table 2. These benchmark results will be compared with results of the optimized structures.

Subsequently, the circular model is optimized, followed by the rectangular model, in two steps:

(i) Creation of thermomechanical metamodels using the response surface methodology (RSM)

(ii) Mono-objective optimization under constraint by a genetic algorithm (GA)

The response surface methodology (RSM) consists of conducting a sequence of experiments to explore the relationships between one variable and multiple-response variables. This method is commonly used in mold optimization problems [24, 25]. For this study, RSM was used to identify geometric parameters influencing the heating time, the temperature difference on the molding surface, and the displacement of the molding surface. The mathematical models created (metamodels) can be used to carry out the optimization with a genetic algorithm (GA).

The low inertia mold concept with rectangular heating channels, whose thermal advantages have been demonstrated previously [20], is based on a laboratory demonstrator mold presented in Figure 4. Optimization variables
TABLE 2: Thermomechanical results for the massive reference mold.

\begin{tabular}{|c|c|c|c|}
\hline & & Water & Oil \\
\hline \multirow{3}{*}{ Reference } & $t_{\text {heating }}(\mathrm{s})$ & 910 & 3659 \\
\hline & $\Delta T\left({ }^{\circ} \mathrm{C}\right)$ & 0.06 & 0.03 \\
\hline & $u_{\max }(\mu \mathrm{m})$ & \multicolumn{2}{|c|}{3.99} \\
\hline
\end{tabular}

associated with this model are presented in Figure 5(b). The finite element model of the circular heating channel mold, optimization variables, and optimization criteria are presented in Figure 5(a) and Table 3.

The levels of each variable are selected according to manufacturing constraints. The variables for the optimization phase for the circular model are $A$, channel diameter; $B$, steel thickness under the channels; $C$, distance between channels and for the rectangular model; $D$, steel thickness under the channels; $E$, half channel width; $F$, channel height; and $G$, distance between the channels. To limit differential expansion problems, the thickness of the steel below and above the channels is identical.

The response surfaces were constructed using Ellistat software and the Latin hypercube sampling (LHD) spacefilling method. This method makes it possible to generate a random distribution of experiments while controlling the number of trials, with the aim of obtaining predictive metamodels that can be used in the optimization phase using a GA.

\section{Results and Discussion}

3.1. Response Surface Methodology. With RSM, it is possible to construct a polynomial regression to create an approximate mathematical function between the factors studied and the responses measured. This equation is the metamodel used later for optimization using a GA. The polynomial model in matrix form is presented in equation (1), with $Y$ the measured response vector, $X$ the test matrix, $\beta$ the column vector of polynomial regression coefficients, and $\varepsilon$ the residual error vector.

$$
Y=X \times \beta+\varepsilon
$$

$\beta$ vector of the regression coefficients can be estimated as $\widehat{\beta}$ using equation (2), with $X^{T}$ the transposed matrix of $X$ :

$$
\widehat{\beta}=\left(X^{T} \cdot X\right)^{-1} \cdot X^{T} \cdot Y \text {. }
$$

A variance analysis, ANOVA, is performed to determine with Fisher factor test factors and interactions that influence the responses observed. The quadratic or cubic metamodels determined have $p$ values $<0.01$ for water-heated metamodels and $p$ values between 0.01 and 0.05 for oil-heated metamodels.

The thermal polynomial metamodels obtained for the circular model are presented in equations (3) and (4) for water heating and equations (5) and (6) for oil heating. The mechanical polynomial metamodel is presented in equation (7) and is the same for water heating and oil heating: 


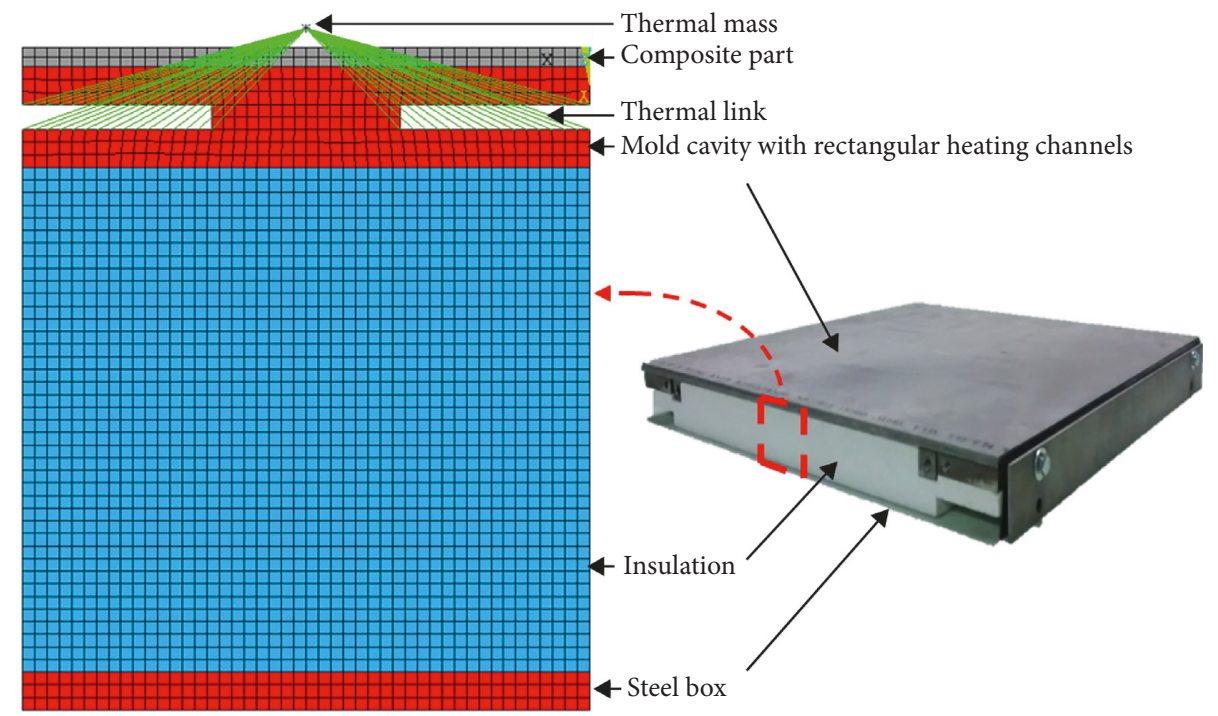

FIgURE 4: Low thermal inertia mold concept with rectangular heating channels and RVE model.

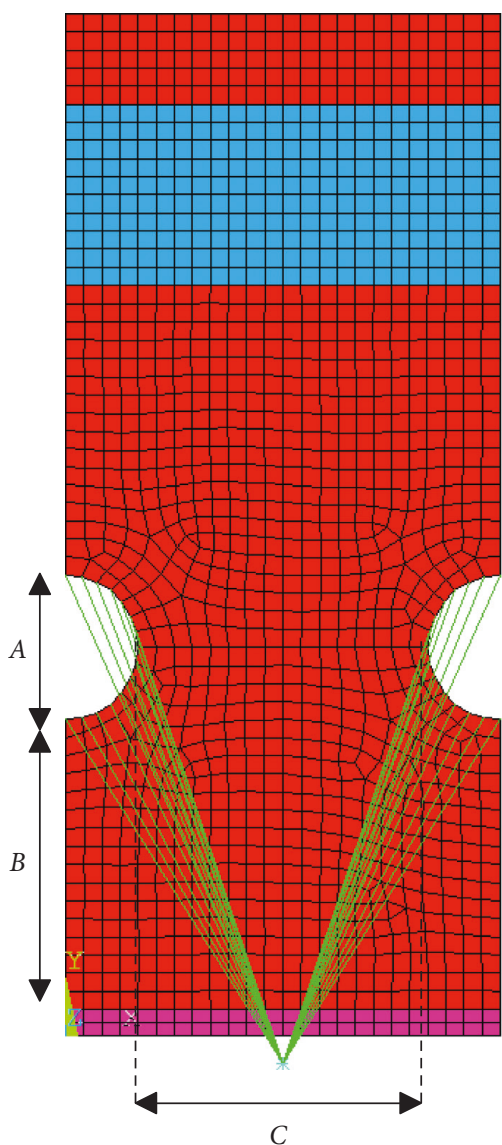

(a)
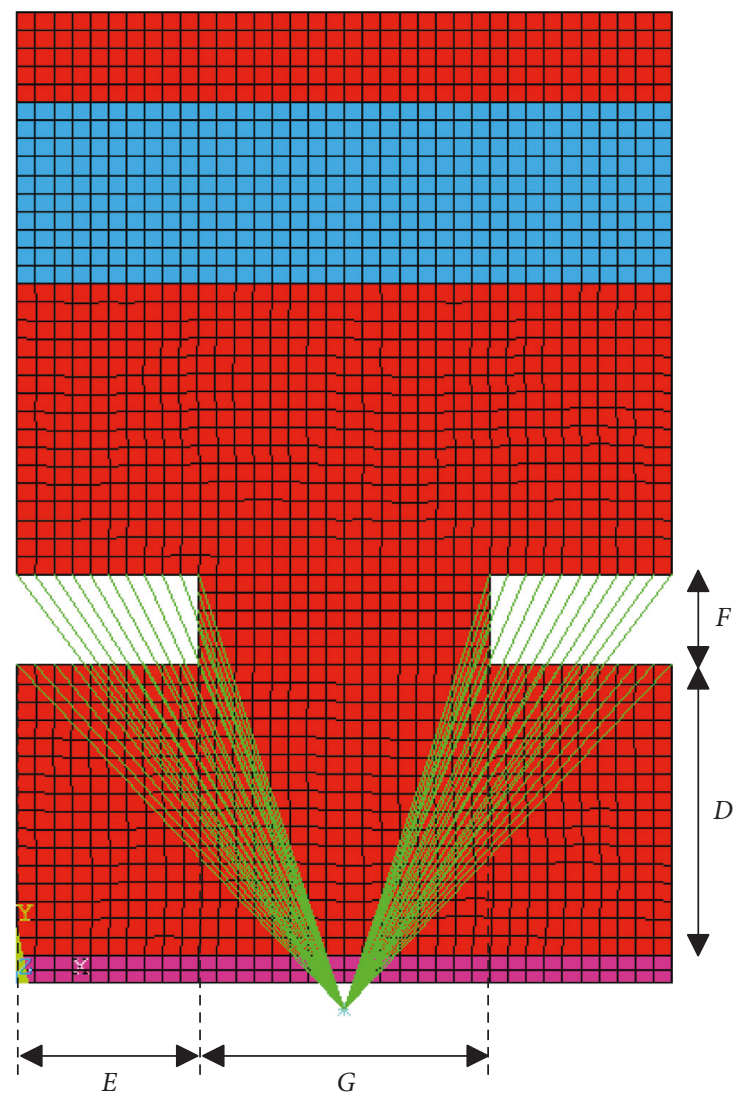

(b)

Figure 5: Models for optimization: (a) circular and (b) rectangular. 
TABLE 3: Variables and optimization criteria for both models.

\begin{tabular}{lcccc}
\hline & \multicolumn{3}{c}{ Min } & Max \\
\hline & $A$ & Channel diameter & $4 \mathrm{~mm}$ & $15 \mathrm{~mm}$ \\
Circular model & $B$ & $\begin{array}{c}\text { Steel thickness } \\
\text { Distance between } \\
\text { channels }\end{array}$ & $2 \mathrm{~mm}$ & $15 \mathrm{~mm}$ \\
& $C$ & $5 \mathrm{~mm}$ & $40 \mathrm{~mm}$ \\
\hline & $D$ & Steel thickness & $2 \mathrm{~mm}$ & $15 \mathrm{~mm}$ \\
Rectangular & $E$ & Half channel width & $5 \mathrm{~mm} \quad 20 \mathrm{~mm}$ \\
model & $F$ & Channel height & $2 \mathrm{~mm}$ & $10 \mathrm{~mm}$ \\
& $G$ & Distance between & $5 \mathrm{~mm}$ & $40 \mathrm{~mm}$ \\
& $t$ & Objective function & Minimize \\
& $\Delta T$ & Constraint function & $<2^{\circ} \mathrm{C}$ \\
& $u$ & Constraint function & $<10 \mu \mathrm{m}$ \\
\hline
\end{tabular}

$$
\begin{aligned}
t_{\text {circular }}^{\text {water }}= & 1617.7-348.1 \times A+59.72 \times B-4.593 \times C \\
& +31.46 \times A^{2}-0.891 \times A^{3}-3.016 \times A B \\
& +0.471 \times A C, \\
\Delta T_{\text {circular }}^{\text {water }}= & 0.295-0.182 \times B+0.074 \times C+0.016 \times B^{2} \\
& +0.003 \times C^{2}+0.001 \times A C-0.013 \times B C, \\
t_{\text {circular }}^{\text {oil }}= & 13614-3183 \times A+359 \times B-79.2 \times C \\
& +266 \times A^{2}-7.44 \times A^{3}-21.5 \times A B+6.21 \times A C,
\end{aligned}
$$

$$
\begin{aligned}
\Delta T_{\text {circular }}^{\text {oil }}= & 0.901-0.453 \times B+0.056 \times B^{2}+0.0022 \\
& \times C^{2}-0.0014 \times B^{3}-0.0061 \times A B \\
& +0.011 \times A C-0.009 \times B C-0.0004 \times A B C \\
u_{\text {circular }}^{\max } & 3.618+0.0456 \times A+0.00148 \times B^{2}+0.00231 \\
& \times A B-0.00011 \times B C
\end{aligned}
$$

The thermal polynomial metamodels obtained for the rectangular model are presented in equations (8) and (9) for water heating and equations (10) and (11) for oil heating. The mechanical polynomial metamodel is presented in equation (12) and is identical for heating with water and with oil:

$$
\begin{aligned}
t_{\text {rectangular }}^{\text {water }} & 450.6+18.51 \times D-10.65 \times E+0.973 \times D^{2} \\
& +0.306 \times E^{2}+0.281 \times F^{2}+0.041 \times G^{2} \\
& -0.036 \times D^{3}-0.003 \times E^{3}-0.145 \times D E \\
& -0.21 \times D F-0.04 \times D G+0.24 \times E F,
\end{aligned}
$$

$$
\begin{aligned}
\Delta T_{\text {rectangular }}^{\text {water }}= & -0.589-0.229 \times D+0.076 \times E \\
& +0.153 \times G+0.015 \times D^{2}-0.002 \times E^{2} \\
& +0.003 \times G^{2}+0.007 \times D F-0.015 \times D G \\
& -0.002 \times E F+0.003 \times E G-0.006 \times F G,
\end{aligned}
$$

$$
\begin{aligned}
t_{\text {rectangular }}^{\text {water }}= & 2273+141 \times D-107 \times E-180 \times F \\
& -8.06 \times G+1.33 \times E^{2}+6.3 \times F^{2}-2.18 \\
& \times D E-1.68 \times D F-0.45 \times D G+3.67 \\
& \times E F+0.36 \times E G+0.78 \times F G, \\
\Delta T_{\text {rectangular }}^{\text {water }}= & 1.73-0.59 \times D+0.14 \times G+0.054 \\
& \times D^{2}-0.0036 \times G^{2}-0.0086 \times D E \\
& -0.029 \times D G-0.009 \times E G-0.0045 \times F G, \\
u_{\text {rectangular }}^{\text {max }} & 15.86-5.13 \times D+0.615 \times D^{2}+0.022 \\
& \times E^{2}-0.019 \times D^{3}-0.0002 \times E^{3}-0.051 \times D E .
\end{aligned}
$$

For each metamodel, correlation coefficients $R^{2}, R_{\text {adj }}^{2}$, and $R_{\text {press }}^{2}$, i.e., the multiple correlation coefficient, the adjusted correlation coefficient, and the predictive correlation coefficient, respectively, were calculated and are presented in Table 4. The multiple correlation coefficient corresponds to the variation explained by the metamodel and therefore to the quality of the regression. Since this criterion tends to increase with the number of experiments, it is preferable to use the adjusted correlation coefficient, which involves the metamodel's degrees of freedom. The predictive correlation coefficient uses a "leave-one-out" cross validation to measure the predictive quality of the metamodel [26]. The correlation coefficients presented in Table 4 confirm the good quality of the mathematical metamodels constructed.

For each metamodel created, it is possible to determine the influence of model parameters on the thermal and mechanical responses. For technological reasons, economic reasons, and production constraints, it is sometimes complex to modify mold's geometric parameters. The correlation between parameter influence and economic/technological/ production constraints can facilitate decision making during the mold's design and sizing phase. The three main influential terms for each metamodel are presented in Table 5.

This parameter influence study revealed that for the circular channel model, the three geometrical parameters have an influence on thermal responses (time and $\Delta T$ ), whereas only parameter $A$ (channel diameter) has an influence on the mechanical response. For the rectangular channel model, parameters $D, E$, and $G$ (steel thickness, half channel width, and channel distance) influence the thermal responses. The mechanical response is essentially driven by parameters $D$ and $E$. Parameter $F$ (channel height) has little influence on the thermomechanical responses on the field studied.

3.2. Optimization with Genetic Algorithm. The genetic algorithm (GA) is an evolutionary algorithm using stochastic methods for the simulation of natural evolution process $[27,28]$. This kind of algorithm is commonly used in singleand multiobjective optimization problems, makes it possible to obtain global optima, and has a recognized robustness and 
TABLE 4: Correlation coefficients of the metamodels.

\begin{tabular}{lcccc}
\hline Metamodel & Equation & $R^{2}$ & $R_{\text {adj }}^{2}$ & $R_{\text {press }}^{2}$ \\
\hline$t_{\text {citer }}^{\text {water }}$ & $(3)$ & 0.972 & 0.968 & 0.954 \\
$\Delta T_{\text {circular }}^{\text {water }}$ & $(4)$ & 0.995 & 0.995 & 0.994 \\
$t_{\text {circular }}^{\text {oil }}$ & $(5)$ & 0.973 & 0.969 & 0.953 \\
$\Delta T_{\text {circular }}^{\text {oil }}$ & $(6)$ & 0.986 & 0.983 & 0.977 \\
$u_{\text {circular }}^{\text {max }}$ & $(7)$ & 0.945 & 0.940 & 0.926 \\
$t_{\text {rectan }}^{\text {water }}$ & $(8)$ & 0.997 & 0.997 & 0.996 \\
$\Delta T_{\text {recter }}^{\text {water }}$ & $(9)$ & 0.997 & 0.996 & 0.996 \\
$t_{\text {rectangular }}^{\text {oil }}$ & $(10)$ & 0.984 & 0.981 & 0.978 \\
$\Delta T_{\text {rectangular }}^{\text {oil }}$ & $(11)$ & 0.981 & 0.980 & 0.977 \\
$u_{\text {rectangular }}^{\text {max }}$ & $(12)$ & 0.852 & 0.842 & 0.811 \\
\hline
\end{tabular}

TABLe 5: Main influential terms for each metamodel.

\begin{tabular}{lcccc}
\hline Metamodel & Equation & Term 1 (\%) & Term 2 (\%) & Term 3 (\%) \\
\hline$t_{\text {citrular }}^{\text {water }}$ & $(3)$ & $B: 47.8$ & $A: 13.4$ & $A B: 12.1$ \\
$\Delta T_{\text {circular }}^{\text {water }}$ & $(4)$ & $A C: 54.3$ & $C^{2}: 22.4$ & $A^{2}: 10.3$ \\
$t_{\text {circular }}^{\text {oil }}$ & $(5)$ & $B: 28.6$ & $A: 18.6$ & $A^{2}: 10.8$ \\
$\Delta T_{\text {circular }}^{\text {O1l }}$ & $(6)$ & $A C: 39.8$ & $C^{2}: 30.8$ & $B C: 10.3$ \\
$u_{\text {circular }}^{\text {max }}$ & $(7)$ & $A: 61$ & $B^{2}: 16.4$ & $A B: 13.8$ \\
$t_{\text {rectannular }}^{\text {water }}$ & $(8)$ & $G: 35.9$ & $E F: 14.2$ & $D E: 11.2$ \\
$\Delta T_{\text {rectangular }}^{\text {water }}$ & $(9)$ & $D G: 50.3$ & $G^{2}: 13$ & $G: 8.35$ \\
$t_{\text {rectangular }}^{\text {oil }}$ & $(10)$ & $E: 27.4$ & $D: 22$ & $E^{2}: 15.7$ \\
$\Delta T_{\text {rectangular }}^{\text {oil }}$ & $(11)$ & $E^{2}: 31.8$ & $D G: 31$ & $D^{2}: 14$ \\
$u_{\text {rectangular }}^{\text {max }}$ & $(12)$ & $D E: 26.4$ & $D: 13.2$ & $D^{2}=E^{2}=11.9$ \\
\hline
\end{tabular}

flexibility of use [29]. The principle of the algorithm is to initialize a population of individuals that, generation after generation, evolve with individuals who are affected by selections, crosses, and mutations. These operations improve the quality of individuals related to the objective function and allow one to move towards the optimal solution. As presented in Table 3, for this study, the objective function consists of the minimization of the heating time, and two constrained functions were applied: controlling $\Delta T$ on the molding surface and maintaining the maximum vertical displacement less than $10 \mu \mathrm{m}$ in order to respect the usual geometrical tolerances of manufacturers. Concerning the maximum temperature difference on the molding surface, a limit of $2^{\circ} \mathrm{C}$ was set to keep the temperature within the limits of a critical thermal case. After having tested various optimization parameters for the GA, the following values were retained: number of generations $=500$; number of individuals per generation $=150$; number of individuals per tournament $=2$; tournament probability $=0.7$; crossover probability $=0.7$; and mutation probability $=0.03$. The overall optimization strategy for this study is presented in Figure 6.

Optimal geometrical parameters for each model, circular and rectangular, heated with water and oil, are presented in Table 6 and Figure 7.

A dimension comparison of steel blocks necessary for manufacturing molds and associated estimated masses are presented in Table 7 when heating channels are manufactured by machining. This comparison highlights the possible reduction of the steel mass in the structure, reducing the

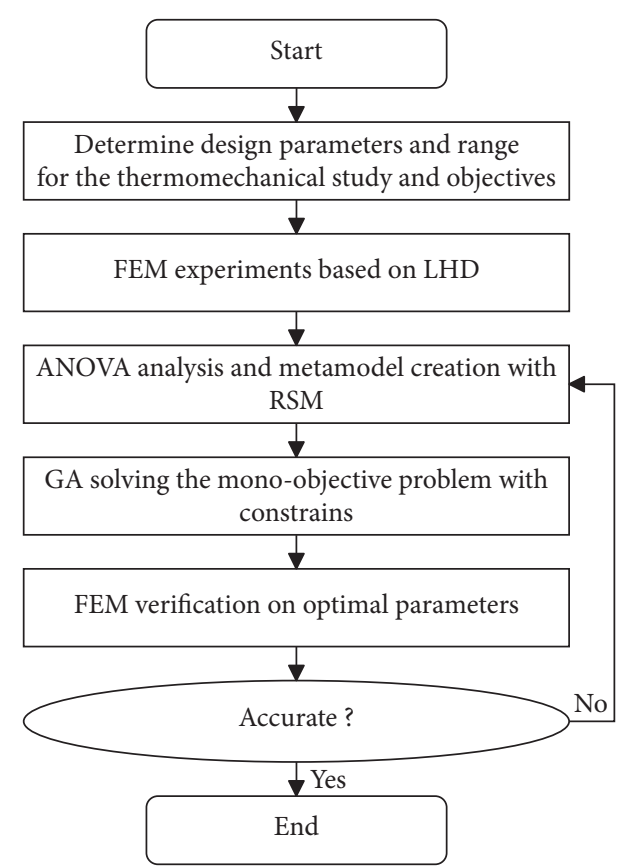

Figure 6: Optimization strategy: study creation, RSM, and GA.

TABle 6: Optimal design parameters.

\begin{tabular}{lccc}
\hline & Parameters & Water & Oil \\
\hline \multirow{3}{*}{ Reference circular } & $A$ & \multicolumn{2}{c}{$8 \mathrm{~mm}$} \\
& $B$ & \multicolumn{2}{c}{$16 \mathrm{~mm}$} \\
& $C$ & \multicolumn{2}{c}{$16 \mathrm{~mm}$} \\
\hline \multirow{3}{*}{ Circular optimized } & $A$ & $9 \mathrm{~mm}$ & $15 \mathrm{~mm}$ \\
& $B$ & $2 \mathrm{~mm}$ & $2 \mathrm{~mm}$ \\
& $C$ & $17 \mathrm{~mm}$ & $5 \mathrm{~mm}$ \\
\hline \multirow{3}{*}{ Rectangular optimized } & $D$ & $2.5 \mathrm{~mm}$ & $5 \mathrm{~mm}$ \\
& $E$ & $18 \mathrm{~mm}$ & $35 \mathrm{~mm}$ \\
& $F$ & $2 \mathrm{~mm}$ & $4.5 \mathrm{~mm}$ \\
& $G$ & $5 \mathrm{~mm}$ & $5 \mathrm{~mm}$ \\
\hline
\end{tabular}

system's heating times or energy consumption, but also making the structure easier to handle. This reduction of the steel mass also makes additive manufacturing processes attractive for which the manufacturing cost is essentially related to the mass of deposited material and not to the complexity of the product.

The predictive results for optimal models using metamodels and the results from thermal finite element verification are compared in Table 8. In the study domain, prediction errors are less than 5\% for thermal metamodels and less than $10 \%$ for the mechanical metamodel, which confirms the quality of metamodels used for optimization.

Comparisons of heating times between the reference model, the circular optimized model, and the rectangular optimized model are presented in Figures 8(a) and 8(b) for water heating and oil heating, respectively.

Concerning water heating, the optimized circular model presented in Figure 7(a) is essentially controlled by thermal aspects. The circular geometry of the channels provides very good rigidity and a good distribution of mechanical stress 


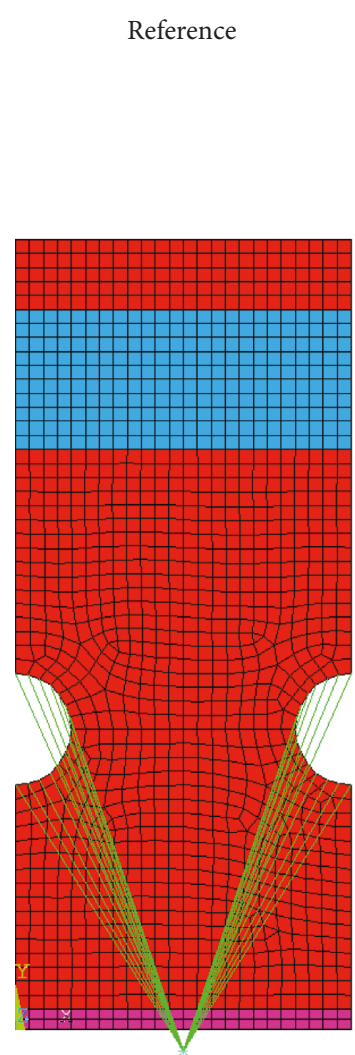

(a)

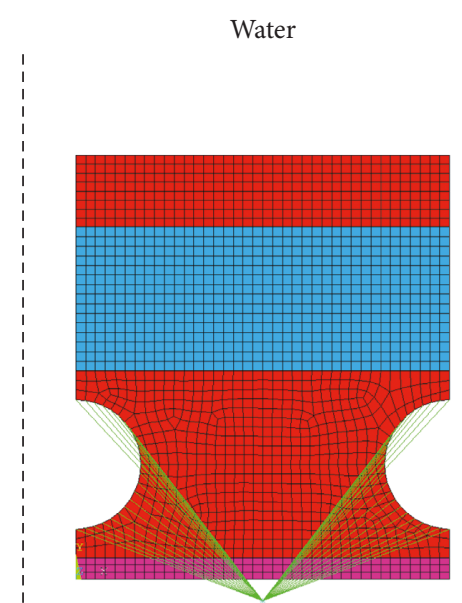

(b)

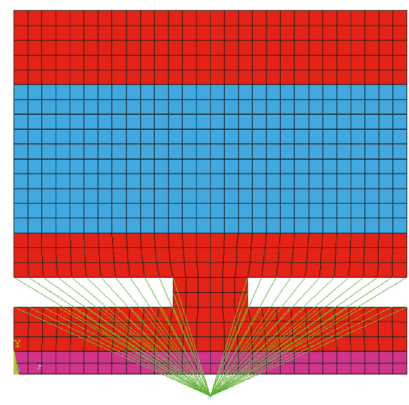

(d)
Oil

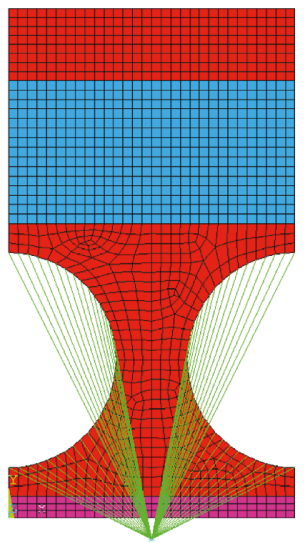

(c)

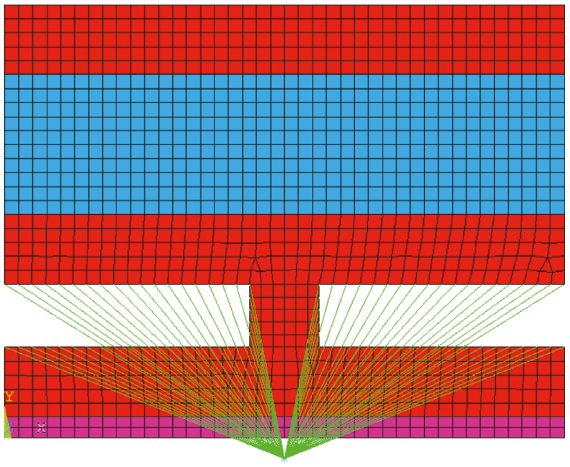

(e)

FIGURE 7: Comparison of (a) the reference model with optimized structures, (b) circular water, (c) circular oil, (d) rectangular water, and (e) rectangular oil.

TABle 7: Steel block dimensions and masses for molds.

\begin{tabular}{ccccc}
\hline Mold & $\begin{array}{c}\text { Steel crude } \\
\text { volume } \\
\left(\mathrm{m}^{3}\right)\end{array}$ & $\begin{array}{c}\text { Steel crude } \\
\text { mass }(\mathrm{kg})\end{array}$ & $\begin{array}{c}\text { Mass after } \\
\text { channel } \\
\text { creation }(\mathrm{kg})\end{array}$ \\
\hline \multirow{4}{*}{ Water } & $\begin{array}{c}\text { Reference } \\
\text { Circular } \\
\text { optimized } \\
\text { Rectangular } \\
\text { optimized }\end{array}$ & $2,51 E^{-02}$ & 195.7 & 185.4 \\
\hline \multirow{4}{*}{ Oil } & $8,15 E^{-03}$ & 63.6 & 51.6 \\
& $\begin{array}{c}\text { Reference } \\
\text { Circular } \\
\text { optimized } \\
\text { Rectangular } \\
\text { optimized }\end{array}$ & $2,51 E^{-02}$ & 34.2 & 26.6 \\
\hline
\end{tabular}

related to mechanical forces. The geometric optimum is the compromise that can minimize the heating time while controlling the temperature difference at $2^{\circ} \mathrm{C}$ on the molding surface. Taking into account technological aspects (pressure drop, pump, and fluid) is essential in this study because it appears that the optimal solution does not completely minimize the spacing between the channels and the diameter of the channels (the mass steel is not fully minimized). Indeed, since the diameter and the distance between the channels decreased, it is necessary to multiply the number of
TABLE 8: Thermomechanical results for optimal mold designs.

\begin{tabular}{|c|c|c|c|c|c|}
\hline & & & $\begin{array}{c}\text { Prediction } \\
\text { RSM } \\
\end{array}$ & $\begin{array}{c}\text { Verification } \\
\text { FEM }\end{array}$ & $\begin{array}{c}\begin{array}{c}\text { Error } \\
(\%)\end{array} \\
\end{array}$ \\
\hline \multirow{6}{*}{$\begin{array}{l}\text { Circular } \\
\text { optimized }\end{array}$} & \multirow{3}{*}{ Water } & $t_{\text {heating }}(\mathrm{s})$ & 442.5 & 472 & 3.1 \\
\hline & & $\Delta T\left({ }^{\circ} \mathrm{C}\right)$ & 1.94 & 1.89 & 0.6 \\
\hline & & $\begin{array}{l}u_{\max } \\
(\mu \mathrm{m})\end{array}$ & 3.99 & 4.03 & 8.5 \\
\hline & \multirow{3}{*}{ Oil } & $t_{\text {heating }}(\mathrm{s})$ & 858 & 799 & 0.8 \\
\hline & & $\Delta T\left({ }^{\circ} \mathrm{C}\right)$ & 0.72 & 0.45 & 3.0 \\
\hline & & $\begin{array}{l}u_{\max } \\
(\mu \mathrm{m})\end{array}$ & 4.24 & 4.51 & 4.6 \\
\hline \multirow{6}{*}{$\begin{array}{l}\text { Rectangular } \\
\text { optimized }\end{array}$} & \multirow{3}{*}{ Water } & $t_{\text {heating }}(\mathrm{s})$ & 395 & 388 & 1.7 \\
\hline & & $\Delta T\left({ }^{\circ} \mathrm{C}\right)$ & 0.62 & 0.64 & 0.1 \\
\hline & & $\begin{array}{l}u_{\max } \\
(\mu \mathrm{m})\end{array}$ & 9.98 & 6.72 & 9.9 \\
\hline & \multirow{3}{*}{ Oil } & $t_{\text {heating }}(\mathrm{s})$ & 372.4 & 430 & 2.2 \\
\hline & & $\Delta T\left({ }^{\circ} \mathrm{C}\right)$ & 0.23 & 0.46 & 1 \\
\hline & & $\begin{array}{l}u_{\max } \\
(\mu \mathrm{m})\end{array}$ & 10.83 & 8.73 & 9.7 \\
\hline
\end{tabular}

channels, which increases pressure drop, reduces operating flow rates, and reduces the convective exchange. The optimal solution for this case study is a geometry that minimizes the steel thickness on both sides of the channels, with a compromise between the diameter of the channels and the 


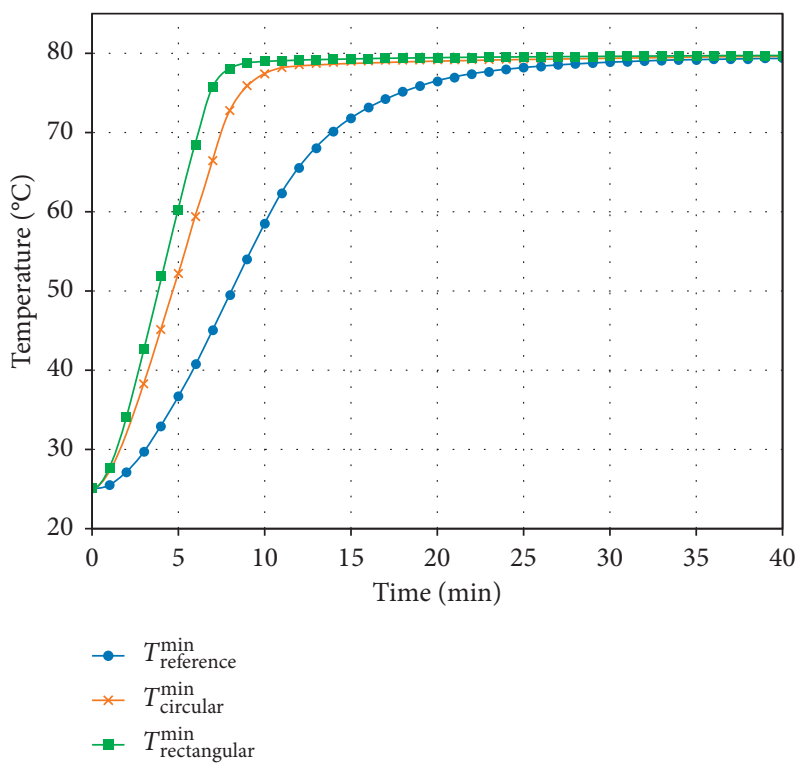

(a)

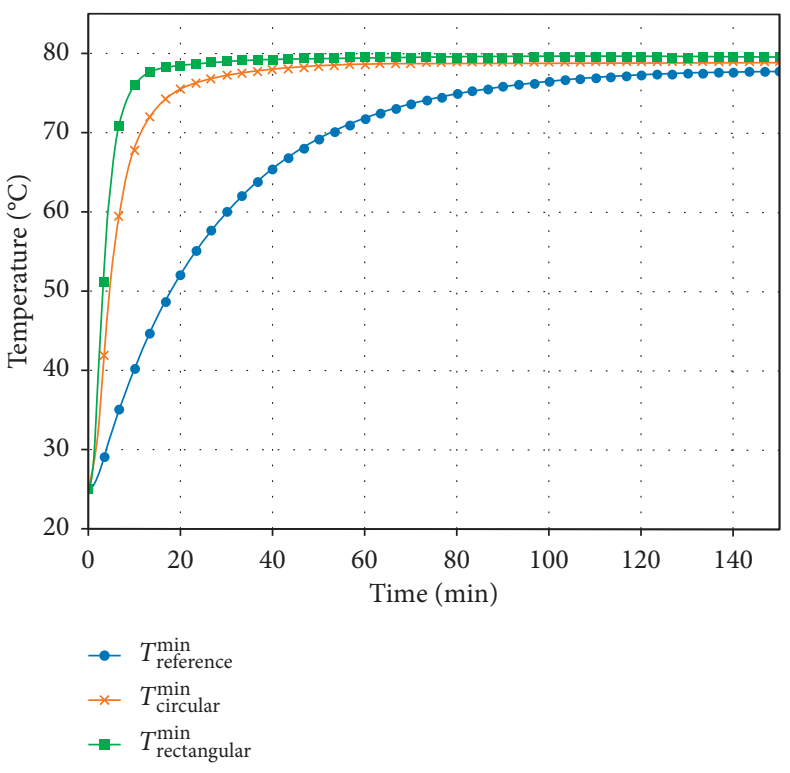

(b)

FIgURE 8: Comparison of heating times with (a) water heating and (b) oil heating.

distance between channels in order to limit the temperature difference on the molding surface while minimizing the mass of steel.

The rectangular heating channel model presented in Figure 7(b) is essentially controlled by mechanical constraints. For this case study, the geometric optimum consists in a geometry that minimizes the distance between channels and the channel height to minimize the steel mass, with a compromise between the width of the channels and the steel thickness on both sides of channels in order to satisfy the mechanical stiffness while limiting the mass of steel.

It appears that with the water heating, the optimization of the circular model allows a $48 \%$ reduction of the heating time compared to the massive reference, while the rectangular model allows a $57 \%$ reduction of the heating time. The transition from optimized circular channels to rectangular optimized channels allows a $20 \%$ reduction of the heating time because the mass to be heated is lower.

Concerning oil heating, the optima obtained for the circular model and the rectangular model, Figures 7(c) and 7 (d), respectively, run into same issues as for water heating, namely,

(i) For the circular model: the small influence of the mechanical constraints and the search for a compromise minimizing the mass while guaranteeing fast and homogeneous heating

(ii) For the rectangular model: the small influence of the homogeneity constraint and the search for a compromise minimizing the mass while guaranteeing good mechanical resistance

However, since the fluid has a higher viscosity than water, the channel geometries obtained for oil-heated models have a larger flow section than channel geometries of water-heated models in order to limit pressure drops.
It appears that with the oil heating, the optimization of the circular model reduces the heating time by $78 \%$, while the rectangular model reduces the heating time by $88 \%$. The transition from optimized circular channels to optimized rectangular channels reduces the heating time by $45 \%$.

Comparison of the thermal responses (heating time and maximum temperature difference on the molding surface) and the mechanical response (maximum vertical displacement) is presented in Figure 9(a) for water heating and Figure 9(b) for oil heating. It seems that for water heating, the optimized circular model is constrained by the $2^{\circ} \mathrm{C}$ limit on $\Delta T$, and the optimized rectangular model is constrained by the $10 \mu \mathrm{m}$ limit on displacement. These are constraints related to the initial objectives set during the optimization phase. On the other hand, for oil heating, the optimized circular model does not present any constraint of this type. Optimization is constrained by physical limitations related to fluid properties and the pressure drop in the system.

Moreover, the gains observed over the heating time also make it possible to reduce the energy cost and the financial cost per injected composite part. Considering that most of the energy cost corresponds to the heating phase of the system, from $t=0 \mathrm{~s}$ to $t=t_{\text {heating, }}$ and without taking into account physicochemical phenomena related to the transformation of the composite, the system's energy balance can be defined by equation (13), with $Q_{s t}$ the thermal energy stored by the system, $Q_{\text {in }}$ the energy provided by the thermoregulator, and $Q_{\text {out }}$ thermal losses.

$$
Q_{\text {st }}-Q_{\text {in }}-Q_{\text {out }}=0 .
$$

The system's energy cost corresponds to the energy $Q_{\text {in }}$ supplied by the thermoregulator during the heating phase and can be calculated using equation (14), with $P$ the heating power and $t_{\text {theating }}$ the heating time. The comparison of heating thermal energies is presented in Table 9. 


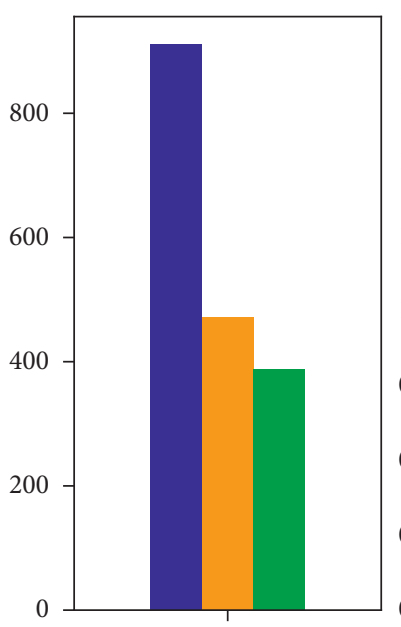

$t(\mathrm{~s})$

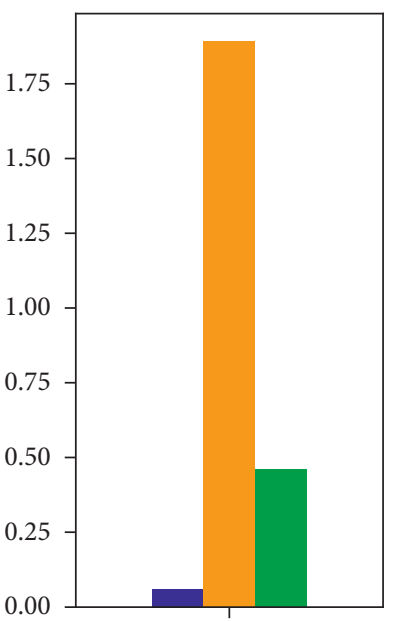

$\Delta T\left({ }^{\circ} \mathrm{C}\right)$

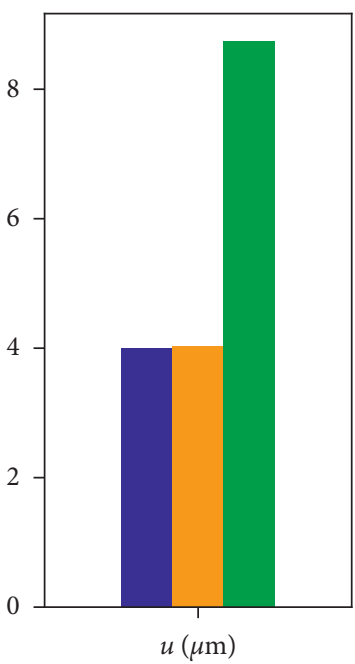

$u(\mu \mathrm{m})$

Rectangular

Circular

Reference

(a)
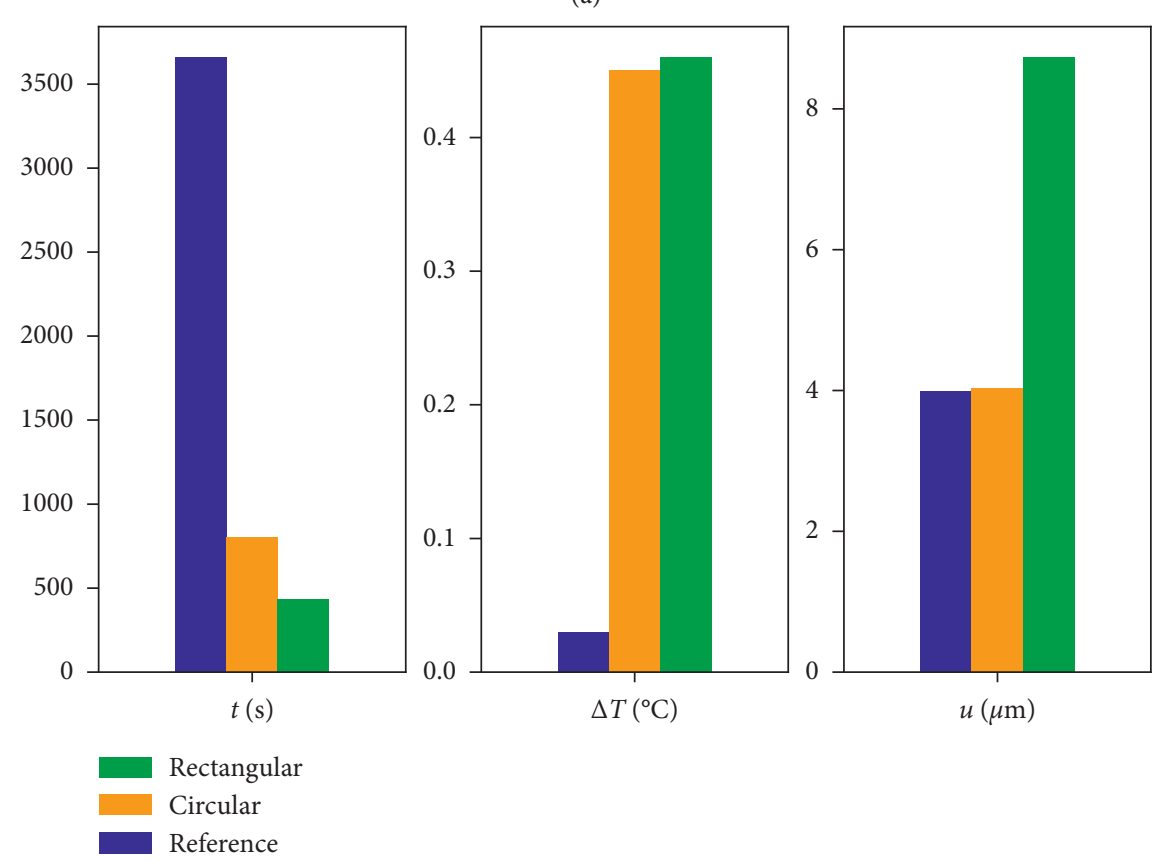

(b)

FIGURE 9: Comparison of thermomechanical responses. (a) Water heating. (b) Oil heating.

TABLE 9: Comparison of heating thermal energy.

\begin{tabular}{lcc}
\hline & $Q(\mathrm{~kJ})$ water & $Q(\mathrm{~kJ})$ oil \\
\hline Reference & 10920 & 43908 \\
Circular optimized & 5664 & 9588 \\
Rectangular optimized & 4656 & 5160 \\
\hline
\end{tabular}

$$
Q=P \times t_{\text {heating }} \text {. }
$$

This study highlights the fact that after optimization, with equivalent heating power and with an equivalent production rate, it is possible to achieve
TABle 10: Optimized geometric parameters.

\begin{tabular}{lccccccc}
\hline \multirow{2}{*}{ Case no. } & \multicolumn{3}{c}{ Circular } & \multicolumn{4}{c}{ Rectangular } \\
& $A$ & $B$ & $C$ & $D$ & $E$ & $F$ & $G$ \\
\hline 0 & 9 & 2 & 17 & 2.5 & 18 & 2 & 5 \\
1 & 8.5 & 2 & 30 & 2.5 & 18 & 2 & 5 \\
2 & 8 & 2 & 40 & 2.5 & 18 & 2 & 5 \\
3 & 8 & 2 & 40 & 2 & 25 & 2 & 5 \\
\hline
\end{tabular}

50-90\% energy savings or with equivalent power and equivalent energy, it is possible to achieve a 50-90\% cycle time reduction. 
TABLE 11: Thermomechanical results.

\begin{tabular}{lccccccccc}
\hline & \multicolumn{2}{c}{ Case 0 } & \multicolumn{2}{c}{ Case 1 } & \multicolumn{2}{c}{ Case 2 } & \multicolumn{2}{c}{ Case 3 } \\
& & RSM $_{\text {pred. }}$ & FEM & RSM $_{\text {pred. }}$ & FEM & RSM $_{\text {pred. }}$ & FEM & RSM \\
& & 442.5 & 472 & 435 & 493 & 428 & 526 & 428 \\
Circular & $\Delta T(\mathrm{~s})$ & 1.94 & 1.89 & 4.7 & 5.1 & 7.5 & 8.6 & 7.5 & 526 \\
& $\Delta T(\mu \mathrm{C})$ & 3.99 & 4.03 & 3.97 & 3.99 & 3.94 & 3.97 & 3.94 & 3.97 \\
\hline \multirow{3}{*}{ Rectangular } & $t(\mathrm{~s})$ & 395 & 388 & 395 & 388 & 395 & 388 & 375 & 367 \\
& $\Delta T\left({ }^{\circ} \mathrm{C}\right)$ & 0.62 & 0.64 & 0.6 & 0.6 & 0.6 & 0.6 & 0.9 & 0.9 \\
& $u(\mu \mathrm{m})$ & 9.98 & 6.72 & 9.97 & 6.72 & 9.97 & 6.72 & 15.27 & 18.00 \\
\hline
\end{tabular}

The optimization carried out with severe thermal and mechanical constraints $\left(\Delta T<2^{\circ} \mathrm{C}\right.$ and $\left.u<10 \mu \mathrm{m}\right)$, case no. 0 , shows that it is possible to obtain between $50 \%$ and $90 \%$ gains on the heating rates (and the energy consumed) depending on the nature of the heat transfer fluid and the geometry of heating channels. Imposed constraint functions seem to be limiting in mold design choices: constraint on the $\Delta T$ seems to be a limitation for the circular channel mold with water heating and constraint on the $u_{\max }$ seems to be a limitation for the rectangular channel mold. Since the needs of manufacturers may differ, three additional studies were conducted to determine what the possible gains could be in presence of lower constraints on $\Delta T$ and $u_{\max }$. Using metamodels determined previously, equations (3)-(12), three new optimizations were carried out with water heating (the most critical case). The associated constraint functions are as follows:

(i) Case 1: $\Delta T<5^{\circ} \mathrm{C}$ and $u_{\max }<10 \mu \mathrm{m}$

(ii) Case 2: $\Delta T<10^{\circ} \mathrm{C}$ and $u_{\max }<10 \mu \mathrm{m}$

(iii) Case 3: $\Delta T<10^{\circ} \mathrm{C}$ and $u_{\max }<20 \mu \mathrm{m}$

The geometrical characteristics obtained after optimization are presented in Table 10 and associated thermomechanical results are presented in Table 11.

Concerning the circular heating channel model, modifying the maximum $\Delta T$ constraint does not change the heating time results. Indeed, theoretical gains on the heating time determined using metamodels are lower than the metamodels' prediction errors. After finite element verifications, it is confirmed that there is no improvement on the heating times of the structure. Optimized results obtained for $\Delta T<2^{\circ} \mathrm{C}$ and $u_{\max }<10 \mu \mathrm{m}$ seem to be the optimal overall solution for the study domain.

Concerning the rectangular heating channel model, the modification of $u_{\max }$ displacement constraint tends to reduce the steel thickness in order to reduce the mass to be heated, while increasing the width of the channel to improve the convective exchange. Finite element verifications confirm that it is possible to reduce the heating time of the structure from $388 \mathrm{~s}$ to $367 \mathrm{~s}$, a gain of $6.5 \%$.

Results presented in this study are good recommendations for the mold industry, but there may be factors which could reduce the gains presented here to a more moderate level. Singularities on a $3 \mathrm{D}$ mold can reduce thermal performances of the system, for example, heat lost along the fluid circulation channel, heat lost in the press, etc. Experiments on an optimized mold prototype will be necessary to validate thermal performances estimated in this study.

\section{Conclusions}

This study, conducted with fixed mold dimensions and fixed heating technologies, makes it possible to study the influence of the main geometrical parameters related to mold thermal performance for a circular model and for a rectangular model. The results obtained in this study for heating from $20^{\circ} \mathrm{C}$ to $80^{\circ} \mathrm{C}$ can be easily transposed to different thermal cycles with higher material transformation temperatures.

The model with circular heating channels has a better mechanical rigidity, and the optimization consists essentially of a compromise to minimize the heating time by reducing the mass, while controlling the temperature difference on the molding surface and the pressure drops. The rectangular channel model provides good thermal homogeneity. The optimization consists of obtaining a compromise to minimize the heating time by reducing the mass, while guaranteeing sufficient mechanical stiffness. The gains observed on the heating time for the optimized circular model, related to the reference structure, are $48 \%$ and $78 \%$, respectively, for water and oil heating. The gains observed for the optimized rectangular model related to the reference model are $57 \%$ and $88 \%$, respectively, for water heating and oil heating. To increase the composite material's production productivity, it appears essential to optimize the mold's thermal performance according to customer needs to obtain a compromise between the heating rate, homogeneity, and mechanical stiffness. The gains observed for the optimized rectangular model, related to the optimized circular model, are $20 \%$ and $47 \%$, respectively, for water and oil heating. These heating time gains are significant on an industrial scale because they are repeated on the heating and cooling phases for a very large number of cycles. It is important to note that gains in heating time were determined in a critical case with a maximum $\Delta T$ of $2^{\circ} \mathrm{C}$ on the molding surface and a maximum displacement of $10 \mu \mathrm{m}$. Complementary studies have highlighted that with these heating technologies (water heating; power, $12 \mathrm{~kW}$ ), a modification of the $\Delta T$ constraint had no influence on the optimal circular model geometry due to the fluid's physical limit, while a modification of the $u_{\max }$ constraint can further reduce the heating time for the rectangular heating channel model.

To conclude, this study confirms the following:

(i) The value of a mold with low thermal inertia to improve the thermomechanical performance of structures 
(ii) The need to take into account the nature of the fluid and technological elements for the design and sizing of a mold

(iii) The advantage of rectangular heating channels in reducing the mold mass

An upcoming numerical study on the influence of technological parameters (volume of fluid, pump, thermoregulator, and nature of the fluid) on thermal performance will be presented in the future and will increase thermal performance and productivity.

\section{Data Availability}

The raw/processed data required to reproduce these findings cannot be shared at this time as the data also form part of an ongoing study.

\section{Disclosure}

Part of this work was presented in the 18th European Conference on Composite Materials (ECCM18).

\section{Conflicts of Interest}

The authors declare that they have no conflicts of interest.

\section{Acknowledgments}

This research was funded by the National Association of Research and Technology (ANRT) under grant no. 2015/1239.

\section{References}

[1] D. V. Rosato and M. G. Rosato, Injection Molding Handbook, Springer, Boston, MA, USA, 3rd edition, 2000.

[2] S. Kitayama, K. Tamada, M. Takano, and S. Aiba, "Numerical optimization of process parameters in plastic injection molding for minimizing weldlines and clamping force using conformal cooling channel," Journal of Manufacturing Processes, vol. 32, pp. 782-790, 2018.

[3] H. S. Park and T. T. Nguyen, "Optimization of injection molding process for car fender in consideration of energy efficiency and product quality," Journal of Computational Design and Engineering, vol. 1, no. 4, pp. 256-265, 2014.

[4] S.-C. Nian, C.-Y. Wu, and M.-S. Huang, "Warpage control of thin-walled injection molding using local mold temperatures," International Communications in Heat and Mass Transfer, vol. 61, pp. 102-110, 2015.

[5] D. Dolkun, W. Zhu, Q. Xu, and Y. Ke, "Optimization of cure profile for thick composite parts based on finite element analysis and genetic algorithm," Journal of Composite $\mathrm{Ma}$ terials, vol. 52, no. 28, pp. 3885-3894, 2018.

[6] S. Asproiu and E. Strajescu, "Influence of mold properties on the quality of molded parts," UPB Scientific Bulletin, Series D: Mechanical Engineering, vol. 69, pp. 39-46, 2007.

[7] R. X. Xu and E. Sachs, "Rapid thermal cycling with low thermal inertia tools," Polymer Engineering \& Science, vol. 49, no. 2, pp. 305-316, 2009.

[8] W. Guilong, Z. Guoqun, L. Huiping, and G. Yanjin, “Analysis of thermal cycling efficiency and optimal design of heating/ cooling systems for rapid heat cycle injection molding process," Materials \& Design, vol. 31, no. 7, pp. 3426-3441, 2010.
[9] C. Xia, J. Fu, J. Lai, X. Yao, and Z. Chen, "Conjugate heat transfer in fractal tree-like channels network heat sink for high-speed motorized spindle cooling," Applied Thermal Engineering, vol. 90, pp. 1032-1042, 2015.

[10] M. Wei, Y. Fan, L. Luo, and G. Flamant, "CFD-based evolutionary algorithm for the realization of target fluid flow distribution among parallel channels," Chemical Engineering Research and Design, vol. 100, pp. 341-352, 2015.

[11] X.-P. Li, G.-Q. Zhao, Y.-J. Guan, and M.-X. Ma, "Optimal design of heating channels for rapid heating cycle injection mold based on response surface and genetic algorithm," Materials \& Design, vol. 30, no. 10, pp. 4317-4323, 2009.

[12] L. Q. Tang, C. Chassapis, and S. Manoochehri, "Optimal cooling system design for multi-cavity injection molding," Finite Elements in Analysis and Design, vol. 26, no. 3, pp. 229-251, 1997.

[13] J. Li, T. Li, X. Peng, F. Liu, H. Zhou, and S. Jiang, “Optimal design of heating system for electrical rapid heat cycle mold based on multi-objective optimization, multiple-attribute decisionmaking, and conformal design theory," Advances in Mechanical Engineering, vol. 10, no. 8, article 168781401878950, 2018.

[14] X. Xu, E. Sachs, and S. Allen, "The design of conformal cooling channels in injection molding tooling," Polymer Engineering \& Science, vol. 41, no. 7, pp. 1265-1279, 2001.

[15] D. E. Dimla, M. Camilotto, and F. Miani, "Design and optimisation of conformal cooling channels in injection moulding tools," Journal of Materials Processing Technology, vol. 164-165, pp. 1294-1300, 2005.

[16] H.-S. Park and X.-P. Dang, "Development of a smart plastic injection mold with conformal cooling channels," Procedia Manufacturing, vol. 10, pp. 48-59, 2017.

[17] Z. Shayfull, S. Sharif, A. MohdZain, R. MohdSaad, and M. A. Fairuz, "Milled groove square shape conformal cooling channels in injection moulding process," Materials and Manufacturing Processes, vol. 28, no. 8, pp. 841-891, 2013.

[18] A. Agazzi, V. Sobotka, R. LeGoff, and Y. Jarny, "Optimal cooling design in injection moulding process-a new approach based on morphological surfaces," Applied Thermal Engineering, vol. 52, no. 1, pp. 170-178, 2013.

[19] K. Altaf, V. R. Raghavan, and A. M. A. Rani, "Comparative thermal analysis of circular and profiled cooling channels for injection mold tools," Journal of Applied Sciences, vol. 11, no. 11, pp. 2068-2071, 2011.

[20] J. Collomb, P. Balland, P. Francescato, Y. Gardet, D. Leh, and P. Saffré, "Thermo-mechanical simulations for the comparison of heating channels geometries for composite material injection tools," Applied Thermal Engineering, vol. 126, pp. 204-211, 2017.

[21] C.-L. Xiao and H.-X. Huang, "Development of a rapid thermal cycling molding with electric heating and water impingement cooling for injection molding applications," Applied Thermal Engineering, vol. 73, no. 1, pp. 712-722, 2014.

[22] C.-L. Xiao, H.-X. Huang, and X. Yang, "Development and application of rapid thermal cycling molding with electric heating for improving surface quality of microcellular injection molded parts," Applied Thermal Engineering, vol. 100, pp. 478-489, 2016.

[23] G. Wang, G. Zhao, H. Li, and Y. Guan, "Research of thermal response simulation and mold structure optimization for rapid heat cycle molding processes, respectively, with steam heating and electric heating," Materials \& Design, vol. 31, no. 1, pp. 382-395, 2010.

[24] G. Wang, G. Zhao, H. Li, and Y. Guan, "Multi-objective optimization design of the heating/cooling channels of the 
steam-heating rapid thermal response mold using particle swarm optimization," International Journal of Thermal Sciences, vol. 50, no. 5, pp. 790-802, 2011.

[25] W. Guilong, G. Zhao, and Y. Guan, "Research on optimum heating system design for rapid thermal response mold with electric heating based on response surface methodology and particle swarm optimization," Journal of Applied Polymer Science, vol. 119, no. 2, pp. 902-921, 2011.

[26] D. Leh, Optimisation du Dimensionnement d'un Réservoir Composite Type IV pour Stockage Très Haute Pression d'hydrogène, Grenoble Alpes, Saint-Martin-d'Hères, France, 2013, https://tel.archives-ouvertes.fr/tel-00942731.

[27] D. E. Goldberg, Genetic Algorithms in Search, Optimization and Machine Learning, Addison-Wesley Longman Publishing Co., Inc., Boston, MA, USA, 1st edition, 1989.

[28] J. H. Holland, "Outline for a logical theory of adaptive systems," Journal of the ACM, vol. 9, no. 3, pp. 297-314, 1962.

[29] E. Zitzler, M. Laumanns, and S. Bleuler, "A tutorial on evolutionary multiobjective optimization," in Metaheuristics Multiobjective Optimization, X. Gandibleux, M. Sevaux, K. Sörensen, and V. T'kindt, Eds., pp. 3-37, Springer, Berlin, Heidelberg, Germany, 2004. 


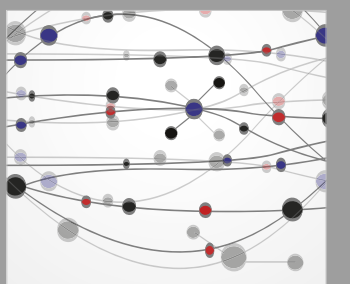

The Scientific World Journal
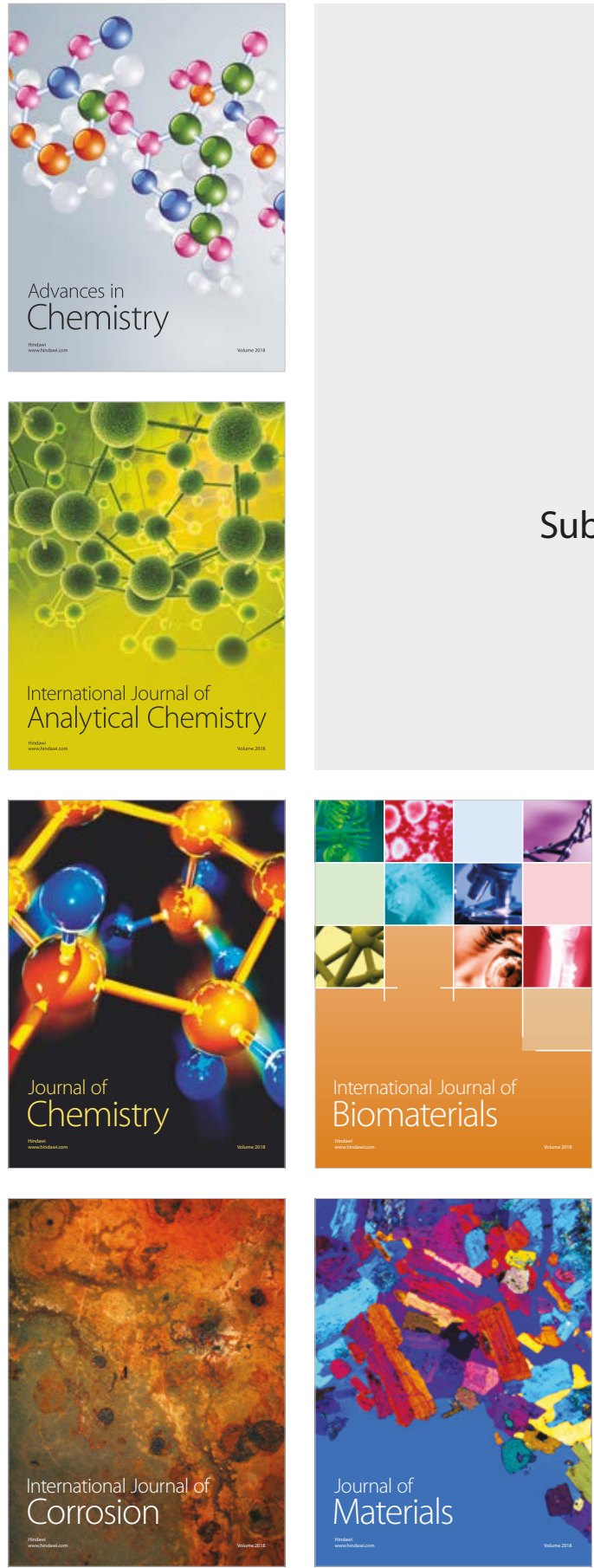

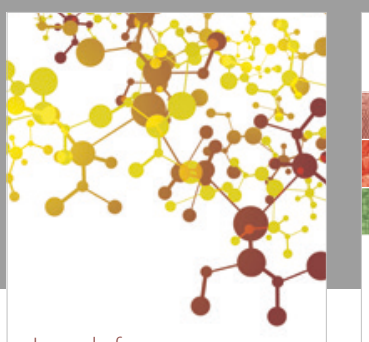

Journal of

Applied Chemistry
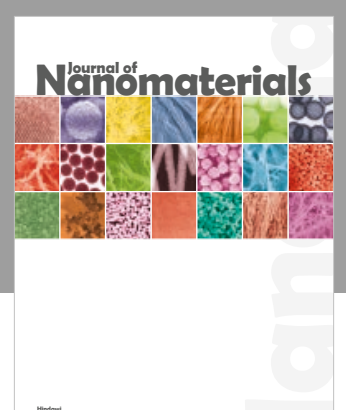

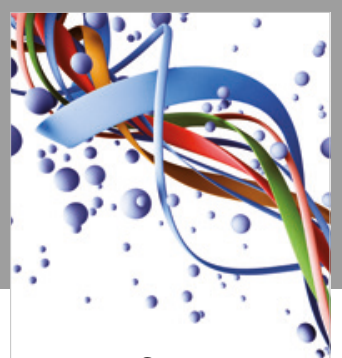

Scientifica

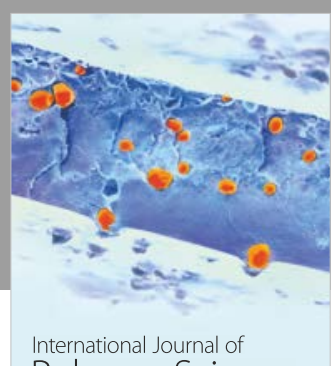

Polymer Science

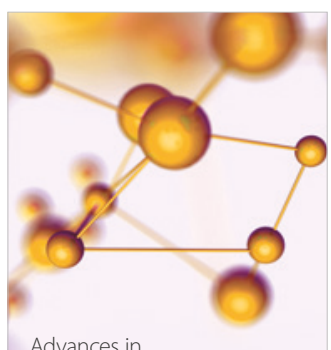

Physical Chemistry
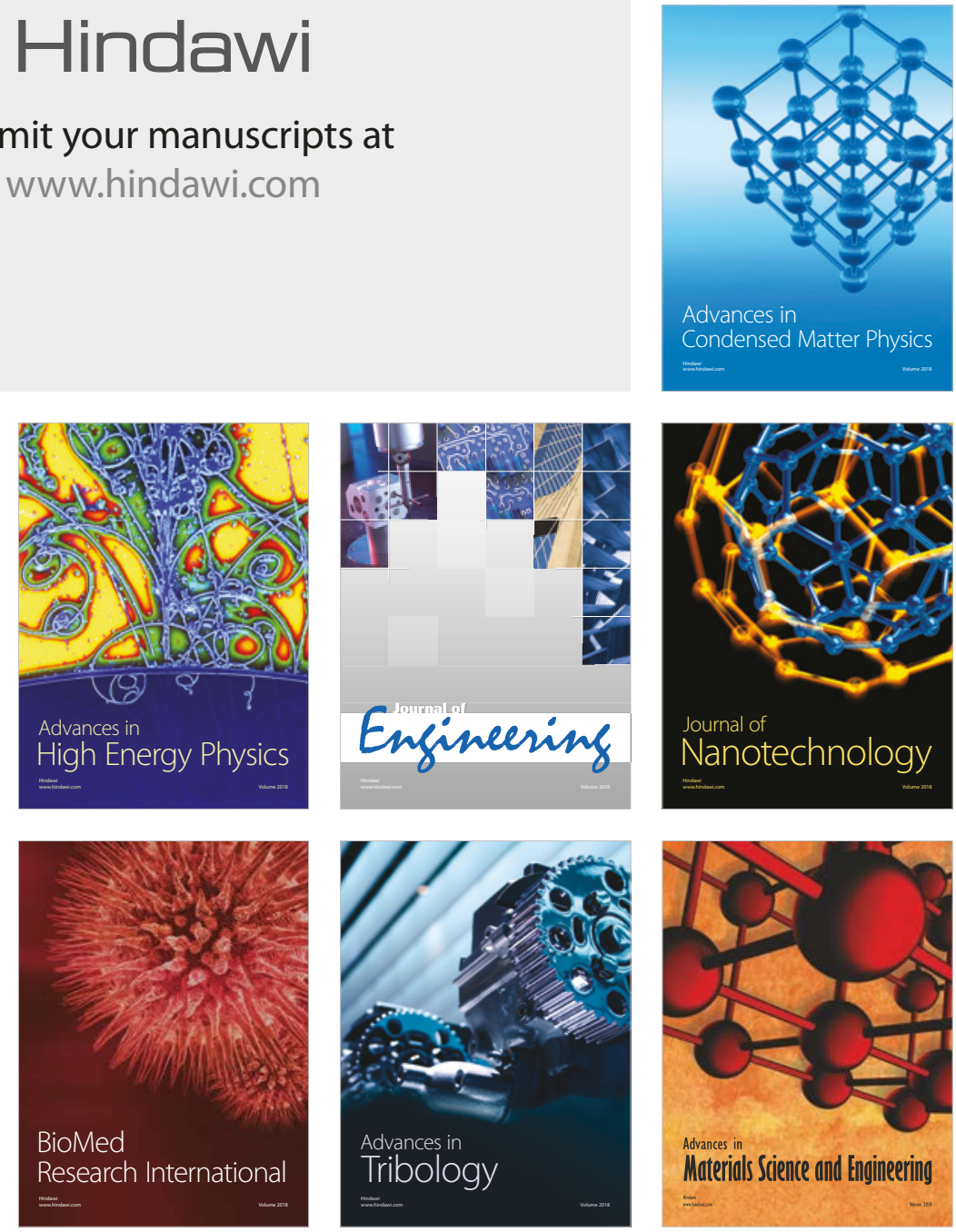